\title{
Polymorphism in Seed Endosperm Proteins (Gliadins and Glutenins) of Turkish Cultivated Einkorn Wheat [Triticum monococcum ssp. monococcum] Landraces
}

\author{
S. KESKIN ŞAN ${ }^{1}$, Ö. ÖZBEK ${ }^{2 *}$, V. ESER ${ }^{1}$ and B. GÖÇMEN TAŞKIN ${ }^{3 *}$ \\ ${ }^{1}$ Central Research Institute for Field Crops, PO Box 226 Ulus, 06042 Ankara, Turkey \\ ${ }^{2}$ Department of Biology, Faculty of Art and Science, Hitit University, Çorum, Turkey \\ ${ }^{3}$ Department of Biology, Faculty of Science, Muğla University, Muğla, Turkey \\ (Received 1 March 2014; Accepted 20 May 2014; \\ Communicated by F. Békés)
}

The objective of this study is the analysis of polymorphism in seed endosperm proteins (gliadins and glutenins) of Turkish cultivated einkorn wheat [Triticum monococcum ssp. monococcum] landraces. The genetic diversity of high-molecular-weight (HMW) glutenin subunits and the gliadin proteins in 10 landrace populations of cultivated einkorn wheat, originating from Turkey, was investigated using sodium dodecyl sulfate polyacrylamide gel electrophoresis (SDS-PAGE) and ammonium lactic acid polyacrylamide gel electrophoresis (A-PAGE), respectively. For glutenins, the mean number of alleles, the mean number of effective alleles, the mean value of genetic diversity and the mean value of average genetic diversity were detected as $3.50,2.98,0.65$ and 0.28 , respectively. The genetic differentiation was 0.57 , while gene flow was 0.19 between populations. For gliadins, the mean number of alleles, the mean number of effective alleles, the mean value of total genetic diversity and the genetic diversity within population were detected as $2.00,1.21,0.17$ and 0.15 , respectively. The genetic differentiation was 0.08 , whereas gene flow was 6.15 between populations. STRUCTURE is a software package program for population genetic analysis, was used to infer population structures of landraces populations. The optimum value for $K$ was obtained as 10. Considering the high number of proteins and genetic variation, and increased interest in organic products, the farming of einkorn wheat should be supported and conservation of germplasm in landraces should be maintained as important genetic resources. The landraces germplasm should be conserved for future crop improvement processes.

Keywords: cultivated einkorn wheat, Triticum monococcum L. ssp. monococcum, genetic variation, high-molecular weight (HMW) glutenin subunits, gliadins

\footnotetext{
* Corresponding authors; E-mails: belgingocmen@hotmail.com, ozbekozlem@gmail.com; Phone: + 90364 2277000/1612; Fax: + 903642277005
} 


\section{Introduction}

Einkorn is a name given to diploid wheat species that all have $A A$ genomes with 14 chromosomes $(2 \mathrm{n}=2 \mathrm{x}=14)$ in the genus Triticum (Waines 1995). Einkorn includes a domesticated, hulled subspecies Triticum monococcum L. ssp. monococcum (with tough rachis), wild subspecies Triticum monococcum L. ssp. boeticum Baiss (with hulled grains and brittle rachis) and Triticum urartu Thum. ex Gandil. According to some authors, Triticum boeticum is a subspecies of Triticum monococcum L. (Kerby and Kuspira 1987; cited in Rodríguez-Quijano et al. 1997) and two domesticated, free threshing subspecies Triticum monococcum L. spp. sinskajae Rilat et Kurk. and Triticum monococcum L. spp. clusii (Filatenko and Kurkiev 1975; Szabó et al. 1994: cited in Vallega 1995). In addition, hybrids between these taxa are fully fertile, whereas those with Triticum urartu Thum. ex Gandil (diploid wheat) are sterile (Dhaliwal 1977).

There have been several research studies, to determine genetic diversity and genetic structure of wild or primitive diploid relatives of tetraploid and hexaploid wheat. Preston et al. (1975) compared gliadin and glutenin compositions of wheat (Triticum aestium), einkorn (Triticum monococcum), A. squarrosa, and S. cereale using the SDS-PAGE method. Metakovsky and Baboev (1992) reported the polymorphism and inheritance of gliadin polypeptides in Triticum monococcum L. Ciaffi et al. (1992) represented through the evaluation of a large collection of wild wheat progenitors consisting of diploid (Triticum boeticum Boiss and Triticum urartu Thum.) and tetraploid wheat (Triticum dicoccoides Körn.) according to their seed storage proteins and their relationships with technological properties. Rodríguez-Quijano et al. (1997) analyzed variations in B-LMW glutenin subunits in 50 einkorn wheat (26 Triticum monococcum, 14 boeticum, and 10 urartu). Ciaffi et al. (1997) assessed gliadin polymorphism in 400 accessions of wild and cultivated einkorn wheat (Triticum monococcum, Triticum boeticum, Triticum boeticum ssp. thaudor and Triticum urartu) using electrophoresis of their proteins. Peşkircioğlu et al. (1998) investigated six types of wild diploid wheat (Aegilops caudata, Aegilops mutica, Aegilops speltoides, Aegilops umbellulata, Triticum monococcum and Triticum urartu) from Turkey using gliadin electrophoresis. Wieser (2000) conducted a comparative investigation of gluten proteins from different wheat species of common wheat (winter wheat, spring wheat, and wheat rye hybrid), hexaploid spelt, tetraploid durum wheat and emmer, and diploid einkorn. Butnaru et al. (2003) assessed morpho-agronomic variability of Triticum monococcum L. landraces in the Timisoara area in Romania. Sofalian and Varizadeh (2009) investigated seed storage proteins in some wild wheat progenitors using SDS-PAGE and ammonium lactic acid polyacrylamide gel electrophoresis (A-PAGE) methods. Hu et al. (2011) analyzed allelic variation and distribution of HMW glutenin subunit 1A-y in Triticum lines using SDS-PAGE method. Waines and Payne (1987) analyzed HMW-glutenin subunits of Triticum monococcum, Triticum urartu and Triticum aestivum using electrophoresis. The genetic variation in diploid wheat was examined previously by investigating isoenzymes systems (Smith-Huerta et al. 1989; Hedge et al. 2000; Karcicio and İzbirak 2003; Goncharov et al. 2007), and morphological characters (Karagöz and Zencirci 2005). Özkan et al. (2007) assessed natural variation and iden- 
tification of microelement content in seeds of 54 einkorn wheat (Triticum monococcum) accessions.

Biochemical markers and DNA-based markers are not affected by environmental factors and are used in several studies to assess genetic diversity and population structure of different species and varieties of wheat. Both of the marker systems have advantages and disadvantages. DNA markers provide great information, assessing the whole genome, on crop taxonomy and evolution, on geographic and ecological aspects of the extent and distribution of genetic diversity. Although, DNA markers produce great genetic variation, those markers occasionally adequately related to agronomic traits (Hodgkin et al. 2001) and additionally they usually screen heterochromatic regions such as the centromeric part. On the other hand, biochemical markers (isoenzymes, gliadins, glutenins, etc.) cover a limited part of the genome, but they are reliable, simple, repeatable and economical. Besides screening for agronomically important characters, they have important effects on the wheat used for making bread and pasta and associated with some trait loci. Particularly, gliadin and glutenin proteins are related with end-use quality of bread and durum wheat (Mac-Ritchie et al. 1990: cited in Rodríguez-Quijano et al. 1997) attract more interest beside their proved use to determine phylogenetic relationships (Metakovsky and Baboev 1992). Therefore, considering the potential of T. monococcum L. ssp. monococcum germplasm as a genetic resource for breeding, and conservation purposes, we preferred seed storage proteins to investigate genetic diversity and population structure in landrace populations.

The seed endosperm proteins, gliadins and glutenins, compose around $80 \%$ of total seed proteins in wheat, $40 \%$ of which are gliadins (Ojaghi and Akhundova 2010). Gliadin proteins are simple polypeptides and separated into $\alpha, \beta, \gamma$, and $\omega$ gliadin subunits by electrophoresis at low $\mathrm{pH}(\mathrm{pH}=3.1)$ (Bushuk and Zillman 1978). The genes encode for gliadin protein subunits are located on the short arms of chromosomes of the first and sixth homeologous groups as forming six Gli loci (Payne et al. 1982). The genes coding for $\omega$, $\alpha, \gamma$, and some $\beta$ gliadins are located on the Gli-1 loci are found on the group 1A, 1B and 1D chromosomes, while the genes coding for $\alpha, \beta$ and $\gamma$ gliadins are located on the Gli-2 loci found on the group 6A, 6B and 6D chromosomes (Metakovsky and Sozinov 1987; Payne et al. 1988). Each Gli locus is bear three to ten genes (Payne 1987) and transferred together as a single Mendelian trait (Sozinov and Poperelya 1980). The products of these linked genes are called gliadin blocks. Genes controlling HMW-glutenin subunits are placed on the long arms of homeologous group 1 chromosomes at loci designated Glu-1 (Payne et al. 1981). The genotypes can be identified directly by the band pattern of HMW-glutenin subunits (Jaradat 2001) because of codominant inheritance or equally dominant alleles encode for major protein subunits (Du Cros and Hare 1985).

Einkorn was cultivated on marginal agricultural land in middle-east and southwestern Europe in the past. In Italy, it is still growing in harsh environments and on impoverished soil (Perrino and Hammer 1984). Today, Triticum monococcum L. is cultivated on a limited scale in Albania, France, Italy, Turkey, and the former Yugoslavia (Harlan 1981; Perrino and Hammer 1982; Perrino et al. 1995). 
In this study, we aimed to find out genetic diversity and population structure of einkorn wheat, which is cultivated mainly on northern part of Turkey, especially in Çankırı, Karabük, Kastamonu, and Sinop provinces. Analyses were made to estimate the following genetic parameters: allele richness $\left(n_{\mathrm{a}}\right)$, the effective number of alleles $\left(n_{\text {ea }}\right)$, genetic diversity $\left(H_{\mathrm{e}}\right)$, genetic differentiation $\left(F_{\mathrm{ST}}\right.$, and $\left.G_{\mathrm{ST}}\right)$ and gene flow $\left(N_{\mathrm{m}}\right)$.

\section{Materials and Methods}

\section{Plant material}

Ten Turkish landrace populations of cultivated einkorn wheat [Triticum monococcum L. ssp. mопососсит] were analyzed using vertical, one-dimensional electrophoresis. The Seed GenBank of the Turkish Ministry of Food, Agriculture, and Livestock (SGB-MFAL) kindly provided the germplasm consisting of seeds, collected as bulk from farmers' fields ( $<5$ ha) from the Çankırı, Karabük, Kastamonu, and Sinop provinces, in 1993, 1994 and 1996. Accession numbers, locations, altitudes, and codes used throughout the text are presented in Table S1*. Collection sites of the populations were located at different altitudes ranging from $350 \mathrm{~m}$ to $1,325 \mathrm{~m}$ in the Northern Transitional Zone of Turkey (Fig. S1). Eleven randomly selected seeds per population were used in the electrophoretic analysis. As controls, we have chosen Cham-1 (C1) and Cham-3 (C3), which were cultivated tetraploid wheat varieties developed and distributed by the International Centre for Agricultural Research in Dry Areas (ICARDA) to compare the electrophoretic patterns with cultivated einkorn wheat landraces.

\section{Analyses of HMW-glutenin subunits and gliadins}

Analyses of HMW-glutenins and gliadins were performed using an SDS-PAGE method for HMW-glutenins previously described by Ng and Bushuk (1987), and an A-PAGE method for gliadins previously described by Bushuk and Zillman (1978) with some modifications. These modified protocols are used in the Cereal Quality Laboratory in ICARDA.

\section{Statistical analysis}

HMW-glutenin subunits and gliadin loci are multiallelic and codominant. The data were scored according to HMW-glutenin subunits, and gliadin band patterns existed in each individual in each of the populations analyzed. For gliadins, band patterns of each individual within and among populations according to number and mobility of gliadin subunit components were compared. The data was scored as binary matrix, if the protein (band) is present (1) or absent (0). The glutenin subunits were scored from the phenotypes of each individual from electrophoretic spectra. The data of both gliadins and glutenins were analyzed using POPGENE version 1.32 (Yeh et al. 1997).

\footnotetext{
* Further details about the Electronic Supplementary Material (ESM) can be found at the end of the article.
} 
Genetic diversity (Nei 1973), estimated within population diversity, was computed as the expected heterozygosity $\left(H_{e}\right)$ based on the allele frequencies at the Glu-A1x, Glu-A1y and Gli-A (Gli-A1 and Gli-A2) loci. The mean number of alleles per locus $\left(n_{a}\right)$ and effective alleles per locus $\left(n_{e a}\right)$ were also calculated. In this study we used $G_{\mathrm{ST}}$ and $F_{\mathrm{ST}}$ to estimate the extent of differentiation according to gliadins and glutenins within and between populations, respectively. Gene flow occurs between populations by seed dispersal, seed exchange or mixing, or cross-pollination. Seed dispersal and cross-pollination are limited, particularly for self-pollinating plant species such as wheat. Seed exchange or mixing of seeds of landraces is common among traditional farmers. Gene flow $\left(N_{\mathrm{m}}\right)$ was also calculated to determine its effect on genetic diversity.

For investigation of population structure, we used the software program STRUCTURE (Pritchard et al. 2000). STRUCTURE provides a model-based on Bayesian approach to explain population structure by using our entire gliadin and glutenin markers data set to identify $K$ clusters to which the program then assigns each individual. We used 110 individuals to infer the optimal value of $K$ (i.e. the number of clusters) by evaluating $K=1-10$. For parameter set, in our model, we selected with admixture as ancestry model and the allele frequencies were assumed to be correlated, since it is more reasonable to assume common ancestry of such closely related populations. The length of burn-in Markov Chain Monte Carlo (MCMC) replications was set to 10,000 and data were collected over $100,000 \mathrm{MCMC}$ replications in run, based on previous literature suggesting that this level is sufficient (Evanno et al. 2005). We determined the optimal value of $K$ using the second order statistics $(\Delta \mathrm{K})$ developed by Evanno et al. (2005) and the ad hoc procedure described by Pritchard et al. (2000).

\section{Results}

\section{Gliadin band pattern analysis of the populations}

A-PAGE generated 82 different gliadin band patterns in 10 Turkish cultivated einkorn wheat landrace populations analyzed. Bands that were too faint were not scored. There were bands with different intensities, but in this study, we did not take into account band intensities. The main differences between the gliadin patterns were presence or absence of one or more bands and slight changes in mobility of the bands. In some of the gliadin patterns, additional bands, which did not exist in other patterns, were detected. Some of the present, absent or additional bands are indicated by an arrow in Fig. S2.

\section{Genetic diversity analysis of gliadins}

According to gene diversity estimates at population level, the highest number of allele $\left(n_{\mathrm{a}}\right)$, the highest number of effective allele $\left(n_{\text {ea }}\right)$ and the highest value of genetic diversity $\left(H_{\mathrm{e}}\right)$ were observed in population $\mathrm{F}$ as $1.87,1.28$ and 0.19 , respectively. The lowest number of allele was detected in population $\mathrm{C}$ as 1.59 , while the lowest number of effective allele, and the lowest value of genetic diversity were detected in population $\mathrm{C}, \mathrm{D}$ and $\mathrm{H}$ as 1.18 , and 0.13 , respectively (Table S2). 
According to overall gene diversity estimates, the mean number of allele $\left(n_{\mathrm{a}}\right)$, number of effective allele $\left(n_{\text {ea }}\right)$, total genetic diversity $\left(H_{\mathrm{t}}\right)$, genetic diversity within population $\left(H_{\mathrm{s}}\right)$, genetic differentiation $\left(G_{\mathrm{ST}}\right)$, and gene flow $\left(N_{\mathrm{m}}\right)$ were $2.00,1.21,0.17,0.15,0.08$, and 6.15, respectively (Table S3).

\section{$H M W$-glutenin subunit analysis of the populations}

According to analysis of HMW-glutenins, seven subunits were identified in total, three for Glu-A1x, and four for Glu-A1y. Glu-A1x encoded subunits were Glu-A1x1, Glu-A1x2*, and Glu-AlxNull. Glu-Aly encoded subunits were compared with subunits 7 and 8, encoded by Glu-Bl of the standard tetraploid wheat variety Cham 1 (C1) (with genome formula $B B A A)$. Glu-Aly subunits were characterized and named as followed: the subunit, which had mobility between subunits 7 and 8 was named Glu-Aly1(y-type1); the subunit, which had equal mobility with subunit 7 was named Glu-A1y2 (y-type2); and the subunit, which had lower mobility than subunit 7 was named Glu-Aly3 (y-type3). Null subunit was also observed among Glu-Aly subunits of diploid einkorn wheat landraces and named as Glu-A1yNull. A representative of HMW-glutenin subunit patterns of Turkish einkorn wheat landraces was given in Fig. S3.

A total of nine different inter-subunit combinations were identified in this study: (Glu-A1x1, Glu-A1y1), (Glu-A1x1, Glu-A1y2), (Glu-A1x1, Glu-A1y3), (Glu-A1x1, Glu-A1yNull), (Glu-A1x2*, Glu-Aly1), (Glu-A1x2*, Glu-A1y2), (Glu-A1x2*, Glu-AlyNull), (Glu-A1xNull, Glu-A1y2), and (Glu-A1xNull, Glu-A1yNull) (Fig. S4). Among these subunit combinations, (Glu-A1x2*, Glu-A1y1) had the highest frequency of approximately $30.91 \%$, which was followed by $(G l u-A 1 x 1$, Glu-Aly2) with a frequency of approximately $19.09 \%$ (Table S4). The frequencies of the remaining subunit combinations were $15.45 \%$ for (Glu-A1x1, Glu-Aly3), $10.00 \%$ for (Glu-A1x2*, Glu-Aly2), $7.27 \%$ for (Glu-A1x1, Glu-AlyNull), 5.45\% for (Glu-A1x1, Glu-A1y1), 2.73\% for (Glu-A1x2*, Glu-A1yNull), $0.91 \%$ for (Glu-A1xNull, Glu-A1y2) and $8.18 \%$ for (Glu-A1xNull, Glu-AlyNull).

\section{Genetic diversity analysis of HMW-glutenins}

For HMW-glutenins, seven alleles were detected in total; three for Glu-Alx and four for Glu-A1y. The highest frequencies for the alleles, encoding subunit 1 (in pops $\mathrm{F}$ and $\mathrm{K}$ ), and subunit $2 *$ (in pops $\mathrm{B}, \mathrm{D}$, and $\mathrm{E}$ ) were 0.91 , while the lowest frequencies were identified as 0.09 for subunit 1 (in pop E), and subunit $2 *$ (in pops F and K) (Table S5). For both types ( $\mathrm{x}$ and $\mathrm{y}$ ) of glutenin subunits, the null subunit was detected in pops $\mathrm{B}, \mathrm{C}, \mathrm{D}$, and $\mathrm{M}$ with frequency of $0.09,0.45,0.09$, and 0.27 , respectively. The highest frequencies for the subunits Glu-Aly1 and Glu-A1y2 were expressed as 0.91 in pops B and D, respectively, while the lowest frequencies for the subunits Glu-Aly1 and Glu-Aly2 were expressed as 0.09 in pops $\mathrm{M}$ and E, respectively. The subunit Glu-Aly3 was the least common subunit among all the subunits. The subunit $G l u-A 1 y 3$ was detected only in pops $\mathrm{H}$ and $\mathrm{K}$ with frequencies of 1.0 and 0.5 , respectively. The null subunit encoded by Glu-Aly was more common than the null subunit encoded by Glu-Alx. The highest frequency for 
Glu-AlyNull subunit was 0.45 , which was detected in pops $\mathrm{C}, \mathrm{K}$, and $\mathrm{M}$, while the lowest frequency for Glu-AlyNull subunit was 0.09 detected in pops B, D and E.

According to overall gene diversity estimates that at population level, the pop $\mathrm{H}$ displayed monomorphism for both x-type and y-type HMW-glutenin subunits, while the pop A displayed monomorphism for only y-type HMW-glutenin subunits (Table S6). The highest number of allele $\left(n_{\mathrm{a}}\right)$, the highest number of effective allele $\left(n_{\mathrm{ea}}\right)$ and the highest value of genetic diversity $\left(H_{\mathrm{e}}\right)$ for x-type HMW-glutenin subunits were observed in pop C as $3.00,2.81$, and 0.68 , respectively, while the lowest number of allele, the lowest number of effective allele, and the lowest value of genetic diversity were observed in pop $\mathrm{H}$ as $1.00,1.00$, and 0.00 , respectively (Table S6). The highest number of allele, the highest number of effective allele and the highest value of genetic diversity for y-type HMW-glutenin subunits were found in pop $\mathrm{M}$ as $3.00,2.37$, and 0.61 , respectively, while the lowest number of allele, the lowest number of effective allele, and the lowest value of genetic diversity was found in pops $\mathrm{A}$ and $\mathrm{H}$ as $1.00,1.00$, and 0.00 , respectively. According to the mean values, the highest number of allele, the highest number of effective allele and the highest value of genetic diversity for HMW-glutenin subunits were observed in pop C as $2.50,2.40$, and 0.60 , respectively, while the lowest number of allele, the lowest number of effective allele, and the lowest value of genetic diversity were observed in pop $\mathrm{H}$ as 1.00 , 1.00 , and 0.00 , respectively.

Overall gene diversity estimates for HMW-glutenin subunits, indicated that y-type subunits displayed higher gene diversity estimates than $\mathrm{x}$-type subunits. The mean value for numbers of allele $\left(n_{\mathrm{a}}\right)$, the mean number of effective allele $\left(n_{\mathrm{ea}}\right)$, the mean value of genetic diversity $\left(H_{e}\right)$, the mean value of average genetic diversity $\left(H_{e_{a} v v}\right)$, genetic differentiation $\left(F_{\mathrm{ST}}\right)$, and gene flow $\left(N_{\mathrm{m}}\right)$ were $3.50,2.98,0.65,0.28,0.57$, and 0.19 , respectively (Table S7).

\section{Population structure}

In order to determine the number of subpopulations, the optimal value for $K$ developed by Evanno et al. (2005) using the second order statistics for STRUCTURE (Fig. S5) identified as 10. It was also confirmed that the ad hoc procedure (Fig. S6) developed by Pritchard et al. (2000). This means that the set of populations were partitioned into 10 clusters. When the colored individual bar plot was examined, some accessions had varying proportions of their genome from other clusters (Fig. S7).

\section{Discussion}

When we compared the results obtained from gliadin electrophoresis in the present study with previous studies; we obtained 82 different gliadin patterns, which were in agreement with 80 (in 109 T. monoccum L. accessions) by Metakovsky and Baboev (1992) and 224 (72 for T. urartu in 150 accessions, 100 for T. boeticum in 160 accessions, and 52 for T. monoccum in 74 accessions) by Ciaffi et al. (1997) and are higher than the gliadin patterns obtained by others; 10 (five for each of $T$. monococcum and A. squarrosa) by Preston et al. (1975), 13 (four different allelic variants for T. boeoticum and nine for T. urartu) by 
Ciaffi et al. (1992), 56 (in 490 T. tauschii accessions) by William et al. (1993). These differences might be existed due to different species, and the number of samples used as representatives of accessions or populations in other studies. The altered mobility of one or a few gliadin components might be the result of a mutational event (Metakovsky 1991). The absence or presence of gliadin products might be explained by the genetic process of diploidisation, gene inactivation, and gene dosage compensation because of differential gene expression. We observed a high number of different gliadin band patterns, which might be the products of different combinations or differential expression of gliadin genes. These combinations might increase the adaptability of $T$. monococcum populations to different environmental conditions. Because diploid wheat has adaptability to different environmental conditions is more stressful than other polyploid wheat, which can buffer genetically the differential environmental stress factor to adapt them (Hancock 1992: cited in Hedge et al. 2000).

The results show that the genetic diversity found in gliadin subunits $\left(H_{\mathrm{t}}=0.17\right)$ is lower compared to previous studies (Preston et al. 1975; Waines and Payne 1987; Ciaffi et al. 1992, 1997; Metakovsky and Baboev 1992; Sofalian and Varizadeh 2009; Hu et al. 2011). However, the genetic diversity of gliadins are still higher than the results obtained from isoenzymes studies (Smith-Huerta et al. 1989; Peşkircioğlu et al. 1998; Hedge et al. 2000; Karcicio et al. 2003), but less polymorphic than Mendlinger and Zohary (1995). For gliadins, we observed the gene flow at a considerably high level and genetic differentiation between populations was not significant in contrast to glutenins observed in this study. This might be explained by the functional seed exchange between traditional farmers, or the same variety of $T$. monococcum L. or the varieties shared with similar genetic background were grown by farmers.

For HMW-glutenin, we observed seven glutenin subunits, which is less than previous studies; 14 Glu $D^{\mathrm{t}} 1$ subunit (490 T. tauschii accessions) by William et al. (1993), 40 subunits for einkorn wheat (26 for T. monococcum and 14 T. boeoticum) and 12 alleles for Glu-A1 locus (seven in T. urartu and five in T. boeoticum) by Ciaffi et al. (1992) and higher than five HMW-glutenin subunits for each T. monococcum and A. squarrosa by Preston et al. (1975). However we observed a genetic diversity high according to HMW-glutenin subunits in contrast to previous studies (Waines and Payne 1987; Rodríguez-Quijano et al. 1997). The differences between our current study and previous studies might be related to sampling strategies and the number of samples analyzed, different species with different genomes and the different experimental methods.

According to overall genetic diversity analysis of the HMW-glutenin subunits, y-type subunits displayed a higher genetic diversity than $\mathrm{x}$-type subunits. The mean numbers of effective alleles for both loci were quite a bit closer to the mean number of allele. It seemed that most of the HMW-glutenin alleles found in landrace populations contributed to gene diversity equally more or less. Latent genetic potential, the difference between the total and effective number of alleles sum up the overall loci (Stebbins and Hartl 1988; Bergmann et al. 1990), represents the populations' capability to preserve adaptability under the multiplicity of changing environmental conditions. The genetic differentiation according to glutenin proteins is considerably high $\left(F_{\mathrm{ST}}=0.59\right)$, that means $59 \%$ of the ge- 
netic diversity is within and $41 \%$ of the genetic diversity between populations. Glu-Al loci expressed more subunits in diploid wheats than cultivated tetraploid and hexaploid wheat. In this study, more probable Glu-Al loci expressed more different HMW-glutenin subunits than gliadin (Gli-A1 and Gli-A2) loci expressed.

The subunits Glu-A1y1 and Glu-A1y2 observed in this study were similar to the subunits observed by Hu et al. (2011) in three species of Triticum monococcum L., Triticum boeticum Boiss and Triticum urartu Tum, while the subunit Glu-Aly3 was characterized as the study of diploid accessions of Triticum aegilopoides by Jiang et al. (2009).

The results also displayed that T. monococcum L. ssp. monococcum populations had a wide variation for $1 \mathrm{Ay}$ alleles as reported by Hu et al. (2011), who reported that the distribution frequencies of the Glu-1Ay subunits in wild wheat varieties such as Triticum turgidum L. ssp. dicoccoides (Körn. ex Asch. et Graebn.) Thell, and Triticum urartu Thum. ex Gandil, were 57.41 and $70.97 \%$, respectively. In this study, we observed the expression of Glu-Aly subunits with a frequency of $81.81 \%$ in Triticum monococcum L. ssp. monococcum landraces populations. Cultivated forms of Triticum turgidum exhibit a higher degree of gene inactivity compared to the wild form. Therefore, a high degree of inactivity at the polyploidy level is not an unexpected result. On the other hand, we found null allele for Glu-Aly subunits. This might also be the result of gene inactivation or a silent gene.

According to the STRUCTURE analysis results, we obtained the optimum value for $K$ is 10. When we examined the individual bar plot (Fig. S7), the pops B (yellow), D (mustard), E (turquoise), $\mathrm{H}$ (pink) and $\mathrm{K}$ (red) displayed distinctive population structures although they had hybrid individuals. The pop C (light brown) represents nearly $50 \%$ of the genetic content from pop D. The pops A, F, G and M all seemed to have more admixed population structure, because, all individuals were hybrids in these populations. However, hybrid individuals were observed in all populations. All populations had genetic content from brown, indigo, and light green colored populations, although those populations had not formed distinctive population structures among the analyzed landraces populations. Actually, the pops A, F, G, and M would be considered as the original population of indigo, brown, light green and green colored populations, respectively. It is more probable, that of the farmers who are currently farming, where those pops (A, F, G and M) were collected might have carried out extensive seed exchange issues with the other farmers. Therefore, those pops (A, F, G, and M) might have undergone some change in their original population structures and have extensive admixed population structures. Consequently we can infer from the STRUCTURE analysis that we have six distinctive populations and four extensively admixed populations.

A wide range of polymorphic levels defines the HMW-glutenin subunits in 10 different landrace populations ranging from polymorphic to monomorphic. Population $\mathrm{H}$ was monomorphic for both the Glu-Al (x and y types) locus and Glu-Aly3 subunit observed only in pops $\mathrm{H}$ and $\mathrm{K}$. Therefore, the distribution of some HMW-glutenin alleles were distributed locally (in only two pops), while other alleles were distributed sporadically (in more than three pops). It has been previously reported by Ciaffi et al. (1993) that the altitude of collection sites seems to be an important criterion. With populations collected at 
locations above $900 \mathrm{~m}$ being less polymorphic than populations collected at lower altitudes (500-700 m), and relative genetic differentiation between populations increasing in those collected at higher altitudes. Nevo et al. (1995) indicated that the determinant factors were temperature and water availability, rather than altitude per se. Findings from previous studies are in contrast to our present results. In our current study, plant materials were collected from four different provinces, located at different altitudes ranging from 350 to $1,325 \mathrm{~m}$. According to our findings, the highest mean number of alleles, and mean values of genetic diversity estimates of gliadins were found in pop G located at $1,020 \mathrm{~m}$ in Karabük Province, and pop C, located at $350 \mathrm{~m}$ in Sinop Province. This might infer that Turkish T. monococcum wheat landraces have adapted to different environmental conditions at quite a wide range and this is expected from landraces formation in their evolutionary history.

Vallega (1979) reported that when einkorn, barley, and durum wheat are grown under adverse environmental conditions, protein production and yield of einkorn wheat equal to or higher than the others did. The amount of protein content of einkorn grain varied from $50 \%$ to $75 \%$, which is higher than the protein content $(12.5 \%$ to $73.5 \%)$ of hard red wheats (Stallknecht et al. 1996). Thus it is consumed by villagers in poor areas and is prepared in a similar style that of ancient civilizations. The einkorn grains were used in various dishes such as soups, salads, casseroles, and sauces (Bond 1989). Therefore, cultivation and improvement of hulled wheat agriculture, particularly Triticum monococcum L. and Triticum turgidum ssp. emmer should be encouraged and supported by governments, just as they support cultivated crop cultivars agriculture.

Although farmers preferred some genotypes according to their agronomical characters and by causing genetic drift, the effects of natural selection was driven by change in climate from year to year, can be accelerated. As a result, genotypes that are able to survive, contribute to the genetic diversity of the germplasm of landrace populations. Therefore, traditional farmers should be encouraged to run seed exchange systems as the maximum functionality so as to prevent unity. Statistical tests (Pearson's correlation, multiple regression, and Principal Component Analyses) indicate that climatic and geographic variables in combination with each other affected genetic diversity of endosperm proteins and isoenzymes at a considerable level in Turkish cultivated emmer wheat landraces (Özbek et al. 2011; Özbek et al. 2012, 2013) as observed in einkorn wheat landraces (data not shown) in this study.

Although Turkish wheat landraces all have great potential, nevertheless, they were not used extensively in breeding programs. In Turkey cultivated bread wheat and durum varieties such as Sivas 111-33, Sertak 52, Ak 702 (Bread wheat) and Kunduru 1149 (Durum wheat) were developed in breeding programs and distributed. In these programs, Turkish wheat landraces have been used as parental Turkish wheat varieties (Karagöz and Zencirci 2005). The Turkish wheat landraces should be managed practically usable efficiently in more breeding programs as genetic resources (Özbek 2014).

In Turkey, ex situ conservation is a commonly used method. The method has some risks to reduce genetic diversity and selection due to interspecific completion, because of strong selection during ex situ regeneration of seeds (Figliuolo and Perrino 2004). The finite pop- 
ulations, which have small sizes have a risk of being subjected to genetic drift over time and thus loose genetic diversity according to genetic theory (Hartl and Clark 1997).

Another limitation for ex situ conservation is the limited number of samples that can be stored in gene banks. Therefore, all the genetic diversity observed in genetic resources of landraces germplasm cannot be conserved in GenBank. In this case, as a complementary system, traditional farming saves the genetic diversity as in situ conservation method. Therefore, to maintain the genetic diversity in landraces, farmers in traditional farming systems should be encouraged to continue traditional farming practices through the financial support of state agricultural regulation laws similar to the support given to modern agricultural farming.

The trade of local seeds is forbidden by State Seed Law (5553) in Turkey. Therefore, farmers can only use the seeds, which are certified by Food, Agriculture, and Livestock Ministry. Recently, traditional farmers investigated a creative way to overcome this legal limitation. In some provinces, the traditional farmers organize seed exchange festivals. They exchange any kind of local plant seeds at these festivals, which are supported and organized by civil organizations like Association of Ecological Producers, and municipality of those provinces. The traditional farmers claim their organic seeds; also they know the importance of those local seeds for ecology, genetic diversity, and future food security of the world. It is also noteworthy; they organize meetings, panels, play dramas, and musicals to acknowledge the people about how important the local seed varieties for future crop improvement and food security during all festivals. These festivals increase the extensive seed exchange between farmers and contribute to germplasm of landraces to obtain more dynamic and diversified genetic structure (Özbek 2014).

Since landraces are the products of traditional farming systems resulting from many years and traditional farmers impute the value on landraces according to economic analysis of variety choice, and ethno botanical information about uses of and toward different varieties (Braush 1991). Therefore the studies on screening the germplasm of landraces, which is recognized as major genetic resources, are vitally important. Particularly the studies about economic analysis, ethno botany, and genetic structure of landraces play an important role for future aspects.

For future crop improvement, food security, and conservation of genetic resources of landraces it is an obligation and an urgent necessity. Therefore, planning conservation programs, the genetic structure, protein content, and genetic composition of important agronomical characteristics should be considered. Turkish wheat landraces should be assessed by detailed analyses to screen the genetic structure, and evolutionary dynamics of populations in order to develop proper conservation strategies. After further evaluation, Turkish wheat landraces could be utilized to improve the breeding of wheat lines, especially for high protein content, and other quality traits, which exist in landraces.

\section{Acknowledgements}

This study was supported by the department of Central Research Institute for Field Crops, The Turkish Ministry of Food, Agriculture and Livestock, Ankara, Turkey. 


\section{References}

Bergmann, F., Gregorius, H.R., Larsen, J.B. 1990. Levels of genetic variation in European silver fir (Abies alba): Are they related to species decline? Genetica 82:1-10.

Bond, A. 1989. Discovering einkorn in Haute Provence, France. Cerealist 1: 6-7.

Braush, S. 1991. A farmer-based approach to conserving crop germplasm. Econ. Bot. 45:153-165.

Bushuk, W., Zillman, R.R. 1978. Wheat cultivar identification by gliadin electro-phoregrams I. Apparatus, method, and nomenclature. Can. J. Plant. Sci. 58:505-515.

Butnaru, G., Sarac, L., Blidar, A., Holly, L., Mar, I. 2003. Morpho-agronomic variability of Triticum monococcum L. landraces in the Timisoara area. In: VII ${ }^{\text {th }}$ International Symposium Interdisciplinary Regional Research - ISIRR, Section IV, Hunedoara, Romania, pp. 167-172.

Ciaffi, M., Dominici, L., Lafiandra, D., Porceddu, E. 1992. Seed storage proteins if wild wheat progenitors and their relationships with technological properties. Hereditas 116:315-322.

Ciaffi, M., Lafiandra, D., Porceddu, E., Benedettelli, S. 1993. Storage protein variation in wild emmer wheat (Triticum turgidum ssp. dicoccoides) from Jordan and Turkey. I. Electrophoretic characterization of genotypes. Theor. Appl. Genet. 86:474-480.

Ciaffi, M., Dominici, L., Lafiandra, D. 1997. Gliadin polymorphism in wild and cultivated einkorn wheats. Theor. Appl. Genet. 94:68-74.

Dhaliwal, H.S. 1977. Origin of Triticum monococcum L. Wheat Information Service 44:14-17.

Du Cros, D.L., Hare, R.A. 1985. Inheritance of gliadin proteins associated with quality in durum wheat. Crop. Sci. 25:674-677.

Evanno, G., Regnaut, S., Goudet, J. 2005. Detecting the number of clusters of individuals using the software STRUCTURE: A simulation study. Mol. Ecol. 14:2611-2620.

Figliuolo, G., Perrino, P. 2004. Genetic diversity and intra-specific phylogeny of Triticum turgidum L. subsp. dicoccon (Schrank) Thell. revealed by RFLPs and SSRs. Genet. Resour. Crop. Evol. 51:519-527.

Filatenko, A.A., Kurkiev, U.K. 1975. A new species - Triticum sinskajae A. Filat. et Kurk. Trudy po Prikladnoi Botanike, Genetike i Selektsii 54:239-241. (in Russian)

Goncharov, N.P., Kondratenko, E. Ja., Bannikova, S.V., Konovalov, A.A., Golovnina, K.A. 2007. Comparative genetic analysis of diploid naked wheat Triticum sinskajae and the progenitor T. monococcum accession. Russ. J. Genet. 43:1248-1256.

Harlan, J.R. 1981. The early history of wheat: Earliest traces to the sack of Rome. In: Evans, L.T., Peacock, W.J. (eds), Wheat Science - Today and Tomorrow. Cambridge University Press, Cambridge, U.K., pp. 1-19.

Hartl, D.L., Clark, A.G. 1997. Principles of Population Genetics. $3^{\text {rd }}$ edn. Sinauser Associates. Sunderland, UK.

Hegde, S.G., Valkoun, J., Waines, J.G. 2000. Genetic diversity in wild wheats and goat grass. Theor. Appl. Genet. 101:309-316.

Hodgkin, T., Roviglioni, R., de Vicente, M.C., Dudnik, N. 2001. Molecular methods in the conservation and use of plant genetic resources. Acta Hortic. 546:107-118.

Hancock, J.F. 1992. Plant Evolution and the Origin of Crop Species. Prentice Hall, NJ, USA.

Hu, X.G., Wu, B.H., Bi, Z.G., Liu, D.C., Zhang, L.Q., Yan, Z.H., Wei, Y.M., Zheng, Y.L. 2011. Allelic variation and distribution of HMW glutenin subunit 1Ay in Triticum species. Genet. Resour. Crop. Evol. 59:491-497.

Jaradat, A.A. 2001. Spatial and temporal genetic structure of wild emmer wheat in Jordan. II. High-molecular-weight glutenins and allozymes. Int. J. Plant Sci. 49:65-76.

Jiang, Q.T., Wei, Y.M., Wang, F., Wang, J.R., Yan, Z.H., Zheng, Y.L. 2009. Characterization and comparative analysis of HMW glutenin 1Ay alleles with differential expressions. BMC Plant Biol. 9:16.

Karagöz, A., Zencirci, N. 2005. Variation in wheat (Triticum spp.) landrace from different altitudes of three regions of Turkey. Genet. Resour. Crop Evol. 52:775-785.

Karcicio, M., İzbirak, A. 2003. Isozymes variations in some Aegilops L. and Triticum L. species collected from Central Anatolia. Turk. J. Bot. 27:433-440.

Kerby, K., Kuspira, J. 1987. The phylogeny of the polyploid wheats Triticum aestivum (bread wheat) and Triticum turgidum (macaroni wheat). Genome 29:722-737.

Mac-Ritchie, F., Du Cross, D.L., Wrigley, C.W. 1990. Flour polypeptides related to wheat quality. Adv. Cereal Sci. Technol. 10:79-145.

Mendlinger, S., Zohary, D. 1995. The extent and structure of genetic variation in species of the Sitopsis group Aegilops. Heredity 74:616-627. 
Metakovsky, E.V., Sozinov, A.A. 1987. Organization, variability and stability of the family of the gliadin-coding genes in wheat: Genetic data gluten proteins. In: Lastity, R., Békés, F. (eds), Proc. $3^{\text {rd }}$ Int. Workshop. Budapest, Hungary, pp. 30-45.

Metakovsky, E.V. 1991. The value of gliadin biotypes in commercial cultivars of wheat. In: Bushuk, W., Tkachuk, R. (eds), Gluten Protein. AACC. St. Paul, MN, USA, pp. 569-580.

Metakovsky, E.V., Baboev, S.K. 1992. Polymorphism and inheritance of gliadin polypeptides in T. monococcum L. Theor. Appl. Genet. 84:971-978.

Nei, M. 1973. Analysis of gene diversity in subdivided populations (population structure/genetic variability/heterozygosity/gene differentiation). Proc. Natl Acad. Sci. U.S.A. 70:3321-3323.

Nevo, E., Pagnotta, M.A., Beiles, A., Porceddu, E. 1995. Wheat storage proteins: Glutenin diversity in wild emmer, Triticum dicoccoides, in Israel and Turkey. 3. Environmental correlates and allozymic association. Theor. Appl. Genet. 91:415-420.

Ng, P.K.W., Bushuk, W. 1987. Glutenin of Marquis wheat as a reference for estimating molecular weights of glutenin subunits by sodium dodecyl sulphate polyacrylamide gel electrophoresis. Cereal Chem. 64:324-327.

Ojaghi, J., Akhundova, E. 2010. Genetic diversity of gliadin pattern, morphological traits and baking quality in doubled haploid wheat. Afr. J. Biotechnol. 9:956-966.

Özbek, Ö. 2014. Turkish wheat landraces: Population structure and function. Emir. J. Food Agric. 26:137-148.

Özbek, Ö., Taskin, B.G., Şan, S.K., Eser, V., Arslan, O. 2011. Gliadin polymorphism in Turkish cultivated emmer wheat (Triticum turgidum L. ssp. dicoccon (Schrank) Thell.) landraces. Plant Syst. Evol. 296:121-135.

Özbek, Ö., Taşkın, B.G., Şan, S.K., Eser, V., Arslan, O. 2012. High-molecular-weight glutenin subunit variation in Turkish emmer wheat [Triticum turgidum L. ssp. dicoccon (Schrank) Thell.] landraces. Plant. Syst. Evol. 298:1795-1804.

Özbek, Ö., Taskin, B.G., Şan, S.K., Eser, V., Arslan, O. 2013. Genetic characterization of Turkish cultivated emmer wheat [Triticum turgidum L. ssp. dicoccon (Schrank) Thell.] landraces based on isoenzyme analysis. Cereal Res. Commun. 41:304-315.

Özkan, H., Brandolini, A., Torun, A., Altıntaş, S., Eker, S., Kılıan, B., Braun, H.J., Salamını, F., Cakmak, I. 2007. Natural variation and identification of microelements content in seed of einkorn wheat (Triticum monococcum). In: Buck, H.T., Nisi, J.E., Salomón, N. (eds), Wheat Production in Stressed Environments. Proc. $7^{\text {th }}$ Int. Wheat Conf., Mar del Plata, Argentina, pp. 455-462.

Payne, P.I. 1987. Genetics of wheat storage proteins and the effect of allelic variation on bread-making quality. Ann. Rev. Plant Physiol. 38:141-153.

Payne, P.I., Corfield, G., Holt, L.M., Blackman, J.A. 1981. Correlation between the inheritance of certain high molecular weight subunits of glutenin and bread making quality in progenies of six crosses of bread wheat. $\mathrm{J}$. Sci. Food Agric. 32:359-371.

Payne, P.I., Holt, L.M., Lawrence, G.J., Law, C.N. 1982. The genetics of gliadin and glutenin, the major storage proteins of the wheat endosperm. Qual. Plant 31:229-241.

Payne, P.I., Holt, L.M., Lister, P.G. 1988. Gli-A3 and Gli-B3, two newly designated loci coding for omega-type gliadins and D subunits of glutenin. In: Miller, T.E., Koebner, R.M.D. (eds), Proc. $7^{\text {th }}$ Int. Wheat Genetics Symp. Press Bath. Bath, UK, pp. 999-1002.

Perrino, P., Laghetti, G., D’Antuono, L.F., Al Ajlouni, M., Kanbertay, M., Szabó, A.T., Hammer, K. 1995. Eco-geographical distribution of hulled wheat species. In: Padulosi, S., Hammer, K., Heller, J. (eds), Proc. First Int. Workshop on Hulled Wheats. Castelvecchio Pascoli, Tuscany, Italy, pp. 100-118.

Perrino, P., Hammer, K. 1982. Triticum monococcum L. and T. dicoccum Schuebler (syn. of T. dicoccon Schrank) are still cultivated in Italy. Presence, collecting, and action. Genetica Agraria 36:343-351.

Perrino, P., Hammer, K. 1984. The farro: further information on its cultivation in Italy, utilization and conservation. Genetica Agraria 38:303-311.

Peşkircioğlu, M., Şehirali, S., Özgen, M. 1998. Identification of wild diploid wheats of Turkey by gliadin electrophoresis. In: Zencirci, N. (ed.), Proc. Int. Symp. on in situ Conservation of Plant Genetic Diversity. Central Research Institute for Field Crops, Ankara, Turkey, pp. 99-107.

Preston, K.R., Woodbury, W., Orth, R.A., Bushuk, W. 1975. Comparison of gliadin and glutenin subunits in the Triticanae by SDS-polyacrylamide gel electrophoresis. Canad. J. Plant Sci. 55:667-672.

Pritchard, J.K., Stevens, M., Donnelly, P. 2000. Inference of population structure using multilocus genotype data. Genetics 155:945-959.

Cereal Research Communications 43, 2015 
Rodríguez-Quijano, M., Nieto-Taladriz, M.T., Carrillo, J.M. 1997. Variation in B-LMW glutenin subunits in Einkorn wheats. Genet. Resour. Crop Evol. 44:539-543.

Smith-Huerta, N.L., Huerta, A.J., Barnhart, D., Waines, J.G. 1989. Genetic diversity in wild diploid wheats Triticum monococcum var. boeoticum and T. urartu (Poaecae). Theor. Appl. Genet. 78:260-264.

Sofalian, O., Varizadeh, M. 2009. Investigation of seed storage proteins in some wild wheat progenitors using SDS-PAGE and ACID-PAGE. Not. Bot. Hort. Agrobot. Cluj 37:179-182.

Sozinov, A.A., Poperelya, F.A. 1980. Genetic classification of prolamines and its use for plant breeding. Ann. Technol. Agric. 29:229-245.

Stallknecht, G.F., Gilbertson, K.M., Ranney, J.E. 1996. Alternative wheat cereals as food grains: Einkorn, emmer, spelt, kamut, and triticale. In: Janick, J. (ed.), Progress in New Crops. ASHS Press. Alexandria, VA, USA, pp. 156-170.

Stebbins, G.L., Hartl, D.L. 1988. Comparative evolution: latent potentials for genetic advance. Proc. Natl Acad. Sci. U.S.A. 85:5141-5145.

Szabó, A.T., Nagytoth, E., Lelley, T. 1994. Studies on Triticeae IX. Strategies for the enhancement of diploid wheats (Triticum sect. urartu and sect. monococcum). Amplicon 4:4-15.

Vallega, V. 1979. Field performance of varieties of Triticum monococcum, T. durum, and Hordeum vulgare grown at two locations. Genetica Agraria 33:363-370.

Vallega, V. 1995. The quality of Tiriticum monococcum L. in perspective. In: Padulosi, S., Hammer, K., Heller, J. (eds), Proc. First Int. Workshop on Hulled Wheats. Castelvecchio Pascoli, Tuscany, Italy, pp. $212-220$.

Waines, J.G., Payne, P.I. 1987. Electrophoretic analysis of the high molecular-weight glutenin subunits of Triticum monococcum, T. urartu, and the A genome of bread wheat (T. aestivum). Theor. Appl. Genet. 74:71-76.

Waines, J.G. 1995. Molecular characterization of einkorn wheat. In: Padulosi, S., Hammer, K., Heller, J. (eds), Proc. First Int. Workshop on Hulled Wheats. Castelvecchio Pascoli, Tuscany, Italy, pp. 193-197.

Wieser, H. 2000. Comparative investigations of gluten proteins from different wheat species. Eur. Food Res. Technol. 211:262-268.

William, M.D.H.M., Peña R.J., Mujeeb-Kazi, A. 1993. Seed storage and isozyme variations in Triticum tauschii (Aegilops squarrosa). Theor. Appl. Genet. 87:257-263.

Yeh, F.C., Yang, R.C., Boyle, T., Ye, Z.H., Mao, J.X. 1997. POPGENE (version 1.32): The user-friendly shareware for population genetic analysis. Molecular Biology and Biotechnology Centre, University of Alberta. Edmonton, Canada.

\section{Electronic Supplementary Material (ESM)}

Electronic Supplementary Material (ESM) associated with this article can be found at the website of CRC at http://www.akademiai.com/content/120427/

Electronic Supplementary Table S1. The locations, altitudes, GenBank accession numbers and population codes of the 10 Turkish landrace populations of cultivated einkorn wheat (T. monococcum ssp. monococcum) used in this study. (Abbreviations: Population Code PC, GenBank Accession Number GB, Sample size N, Collection Year CY, Altitude AL)

Electronic Supplementary Table S2. The mean values and standard deviation estimates of genetic variation and heterozygosity statistics of gliadin subunits in each of 10 Turkish cultivated einkorn wheat

$$
\text { [T. monococcum L. ssp. monococcum] landrace populations }
$$

Electronic Supplementary Table S3. Overall mean values and standard deviation estimates of genetic variation and heterozygosity statistics of gliadin subunits in 10 Turkish cultivated einkorn wheat

[T. monococcum L. ssp. monococcum] landrace populations 
Electronic Supplementary Table S4. The percentage of x-type and y-type HMW-glutenin inter-subunit combinations identified in Turkish cultivated einkorn wheat [T. monococcum L. ssp. monococcum] landrace populations. (Abbreviations: Number of individual, in which the subunit combinations were observed NI, frequency \%)

Electronic Supplementary Table S5. Allele frequencies of HMW-glutenin subunits (x-type and y-type) in 10

Turkish cultivated einkorn wheat [T. monococcum L. ssp. monococcum] landrace populations (Abbreviations: alleles for $\mathrm{x}$-type: subunit $1 \mathrm{~A}$, subunit $2 * \mathrm{~B}$, subunit null $\mathrm{C}$; alleles for $\mathrm{y}$-type: subunit y-type1 A, subunit y-type2 B, subunit y-type3 C, subunit null D)

Electronic Supplementary Table S6. Genetic variation and heterozygosity statistics estimates of HMW-glutenin subunits in Turkish cultivated einkorn wheat [T. monococcum L. ssp. monococcum] landrace populations

Electronic Supplementary Table S7. Overall genetic diversity estimates of HMW-glutenin subunits in 10 Turkish cultivated einkorn wheat [T. monococcum L. ssp. monococcum] landrace populations

Electronic Supplementary Figure S1. a. A geographical map of Turkey; b. A map of north part of Turkey, showing the geographical distribution of 10 Turkish cultivated einkorn wheat [Triticum monococcum L. ssp. monococcum] landrace populations used in this study

Electronic Supplementary Figure S2. Comparison of gliadin electrophoretic patterns on A-PAGE of 10 Turkish cultivated einkorn wheat [Triticum monococcum L. ssp. monococcum] landraces. Population A (lines 1-9), population B (lines 10-17), population C (lines 18-24), population D (lines 25-31), population E (lines 32-38), population F (lines 39-40), population G (lines 41-47), population H (lines 57-62), population K (lines 63-72), and population M (lines 73-82). Cham-1 (C1) and Cham-3 (C3), which were durum wheat varieties, were used as standards

Electronic Supplementary Figure S3. HMW-glutenin subunit patterns observed in Turkish cultivated einkorn wheat [Triticum monococcum L. ssp. monococcum] landrace populations. Cham-1 (C1), which was a durum wheat variety, was used as standard. In figure, capital letters and numbers represent population codes and sample numbers, which were given in this study, for example A1: the first sample from population A

Electronic Supplementary Figure S4. HMW-glutenin inter-subunit profiles identified in Turkish cultivated einkorn wheat [Triticum monococcum L. ssp. monococcum] landrace populations. Cham-1 (C1) and Cham-3 (C3), which are durum wheat varieties, were used as standards

Electronic Supplementary Figure S5. The second order statistics $(\Delta \mathrm{K})$ developed by Evanno et al. (2005) for STRUCTURE in order to determine the number of subpopulations identified the optimal value for $\mathrm{K}$

Electronic Supplementary Figure S6. The ad hoc procedure described by Pritchard et al. (2000) to determine the number of subpopulations identified the optimal value for $K$

Electronic Supplementary Figure S7. Turkish cultivated einkorn wheat [Triticum monococcum L. ssp. monococcum] landraces population structure based on Bayesian inference among 10 populations

(110 individuals) analyzed with endosperm protein assuming $K=10$ 